\title{
Garcia de Orta e Alexander von Humboldt Diálogo entre o longe e o longe (Lisboa - Goa)
}

\author{
Anabela Mendes
}

Grande meada temos para desempeçar e

grandes nós para desatar ...

1.

Mahabharata

enc. Irathakulangara

Rama Varrior

Kerala Kathakali Center

(Kathakalimandapam)

Fort Kochi, 2008, fot. Anabela Mendes.

In Coloquios dos

Simples he drogase cousas medicinais da

India, e assim de algumas

frutas achadas nela ond se tratam algumas cousas

tocantes a medicina

prática, e outras cousas boas, edição impressa em Goa, em 10 de Abril de

1563, reprodução facsmilada, Lisboa, Academia das Ciências, 1963, p. 45.

Anabela Mendes

é Professora na Faculdade de Letras da Universidade de Lisboa.
Foi ao "Colóquio 11", dedicado por Garcia de Orta ao cardamomo, à malagueta e à caranda (sabe a uva, mas pode ser usada para fazer achar) que pedi de empréstimo a sua abertura para uma epigrafe, com a qual convivi ao longo de um ano e três meses (ainda não a abandonei...) o tempo de preparação do Projecto de Goa, chamemosIhe assim. Forneceu-me o médico e botânico português do séc. XVI o mote nas palavras e na sua expansão, ao comparar-se ele próprio ao Grande Alexandre da Macedónia, não nos feitos, mas nas dificuldades, e assim me ensinou também que a paciência é uma qualidade essencial para estabelecer diálogo entre o longe e o longe.

Lisboa e Goa estão hoje à distância de 24 horas de avião. A experiência dá a ver que esse tempo se dilata muito para além dessa nossa percepção do tempo real, quando entramos numa outra cultura e num horizonte civilizacional de grande complexidade. Goa é, de certa maneira, um lugar suspenso entre culturas, religiões e costumes. Entre a Velha Goa, onde a História, a Arquitectura a Arte e o culto religioso católico se entretecem numa miragem antiga, e a Nova Goa - mais conhecida como Pangim (para os portugueses) Panjim (para os ingleses), Panaji (para os indianos a partir de 1961), mas ainda Ponnje em concanim, a língua local, que continua a ser ensinada nas escolas -, circulam mundos vibrantes de contrastes cheios de mistérios e enigmas.

De uma enorme doçura e profunda afabilidade, os goeses parecem ocultar em si mesmos o secreto modo de como vêem a vida, de como nela são iniciados. Sempre que nos perguntamos: "0 que estarão de facto a pensar?" "Que haverá para além do olhar brilhante e do sorriso que deslumbra?", jamais seremos respondidos, porque qualque que fosse a resposta, ela nunca identificaria aquilo que desejamos saber de alguém que não se deixa a si próprio roubar.

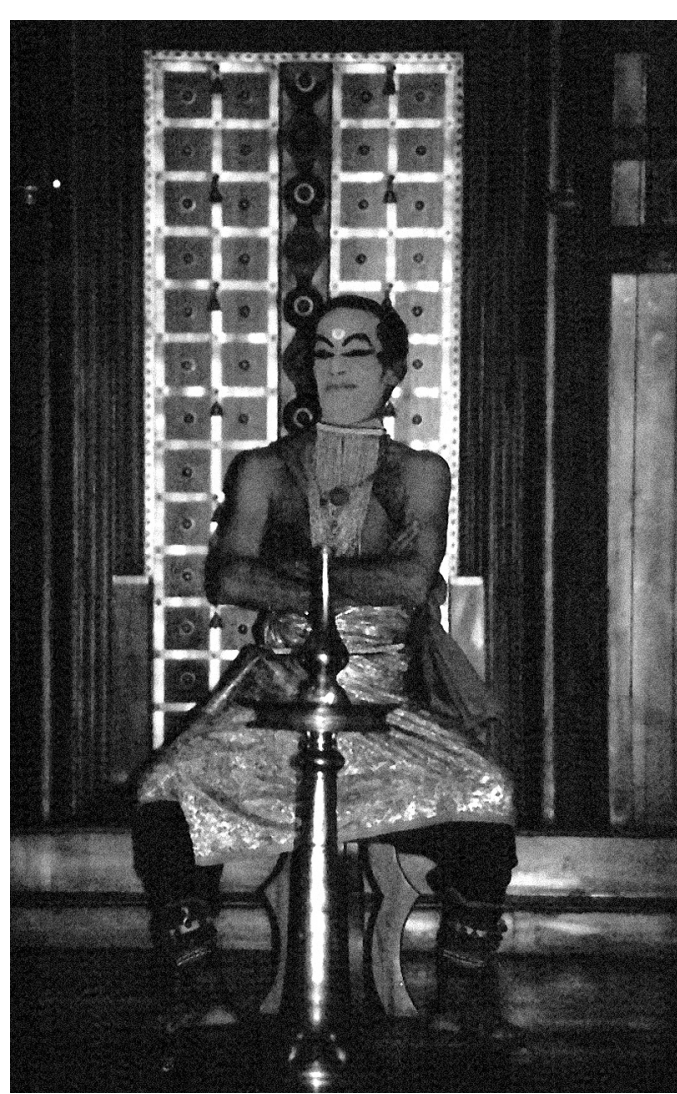

2.

A nossa viagem a Goa (23.11.-29.11.2008) nasceu com um projecto entre culturas, em torno dos cientistas, humanistas e viajantes Garcia de Orta (1501-1568) e Alexander von Humboldt (1769-1859). A Europa foi berço de ambos, à distância de três séculos, tendo-Ihes concedido, 
a cada um e segundo as suas particularidades, ampla matriz cultural e civilizacional. E foi justamente essa formação em espírito aberto e crítico que fez despontar inconformismo e inadaptação perante um meio hostil, retrógrado e provinciano, em Orta e Humboldt. 0 primeiro procura largueza de vistas e saberes em terras indianas, o segundo aventura-se nas ciências, a que chamaríamos hoje do ambiente, e pratica-as em viagem e em laboratório natural, cruzando rotas tão distantes como o continente americano e o continente asiático até às fronteiras com a China.

Experimentámos o diálogo entre os dois viajantes em projecto português (Lisboa, Maio de 2007), internacional e transdisciplinar, e em projecto europeu (Colónia, Setembro de 2007) de âmbito idêntico. A realização e participação nestes encontros científicos e a apresentação de um espectáculo em Lisboa despertaram a nossa vontade de ir mais além. A inspiração de vida fascinante e aventurosa dos nossos mestres Orta e Humboldt impeliu-nos para que tentássemos aprender a conhecer, pelo menos um dos lugares, sobre os quais tão miticamente trabalhávamos há tanto tempo. É claro que não era o conhecimento museológico que procurávamos. Esse estava nos livros, nos arquivos, talvez em alguns mapas e desenhos. Quisemos então experimentar a comunicação viva com indianos. Propusemos a europeus de Lisboa, Paris e Colónia a partilha de uma pequena embaixada de Ocidente para Oriente. Convidámos portugueses e indianos a viverem em Goa, Bangalore, Bombaim, e Trichur, que connosco marcassem encontro na cidade que, em 1534, recebera para sempre o médico, farmacologista e botânico de Portugal.

Chegámos ao destino vindos de diferentes rotas, espalhámo-nos pela Pangim de muitas grafias e sinestesias, virada sobre o rio Mandovi e o Mar Arábico. Muitos de nós optaram por habitar num antigo solar do séc. XVII, hoje transformado em modesta estalagem, no Bairro das Fontainhas, ainda o mais português de todos os lugares em Goa, e aquele onde as portadas das janelas conservam incrustadas filas de fragmentos em madrepérola como coadores de luz desde há centenas de anos.

3.

Elegemos a cidade de Goa como aquele simbólico lugar a oriente que, em sentido lato, podia, nem que fosse por uma só vez, associar a Europa à Ásia com um programa cultural e científico com suporte na transversalidade e no mútuo enriquecimento, realizado a pensar no futuro, naquele futuro que cada um de nós também seria capaz de construir se quisesse verdadeiramente manter as pontes entre o longe e o longe. Aí teve lugar, no International Centre de Goa (Dona Paula), durante dois dias, o último colóquio internacional e transdisciplinar, intitulado Garcia de Orta and Alexander von Humboldt: Across the East and the West. A Universidade de Goa recebeu o lançamento do primeiro Livro de Actas deste projecto, uma palestra sobre Sophia de Mello Breyner e outra sobre "0 português na Ásia". 0 CLP - Instituto Camões em Goa abriu as suas portas para a oficina de movimento (ver aqui texto de Alexandre Calado pp. 71-73). Em Alto Porvorim, pequena aldeia a norte de Goa, 0 Centro S. Francisco Xavier de Investigação Histórica recebeu uma sessão de leituras de poesia portuguesa. De volta ao Bairro das Fontainhas, numa casa de arquitectura indo-portuguesa, adquirida e recuperada pela Fundação Oriente, tiveram lugar a exposição de fotografia designada de Portulindia e a apresentação da peça de teatro Por mares já há muito navegados.

\section{4.}

A peça de teatro Por mares já há muito navegados (transformação de um ponto de vista a partir do verso de Camões), escrita em 2007, foi concebida com o propósito de adequar a ideia de colóquio às duas figuras inspiradoras deste projecto trifásico. Alexander von Humboldt e Garcia de Orta mantêm regular conversação com interlocutores privilegiados. 0 primeiro, com o seu acompanhante de viagem ao continente americano, o médico e botânico francês Aimé Bonpland (1773-1858; o segundo, em viagem mental, com uma personagem inventada e de natureza retórica, Ruano, criada por Orta em Colóquios dos simples para mais habilmente se defender do ponto de vista relacionado com o conhecimento científico tradicional e mais ortodoxo, e do qual o botânico português se sentia já muito distante. A argumentação entre as duas vozes ganha assim mais relevo, ao mesmo tempo que Ruano desempenha ainda, na criação literária ortiana, a função de produzir com regularidade discurso fático apropriado, de tal modo que a obra adquira maior vivacidade e se torne mais acessivel a sua compreensão para os leitores não especializados.

A partir destas premissas nasceram desdobramentos de personagens a pares e em curtos recortes, numa progressão que se quis do presente para o passado e de ocidente para oriente. A linguagem utilizada em cada cena evolui da palavra ou curta expressão em série, como enunciação de nomes ou expressões que identificam o tributo do mundo ao cientista alemão Alexander von Humboldt, passando pelo discurso com abundante 


\section{$<2>3$ \\ $\checkmark 4$ \\ Mahabharata, enc. Irathakulangara \\ Rama Varrior, \\ Kerala Kathakali Center (Kathakalimandapam), \\ Fort Kochi, 2008, fot. Anabela Mendes.}

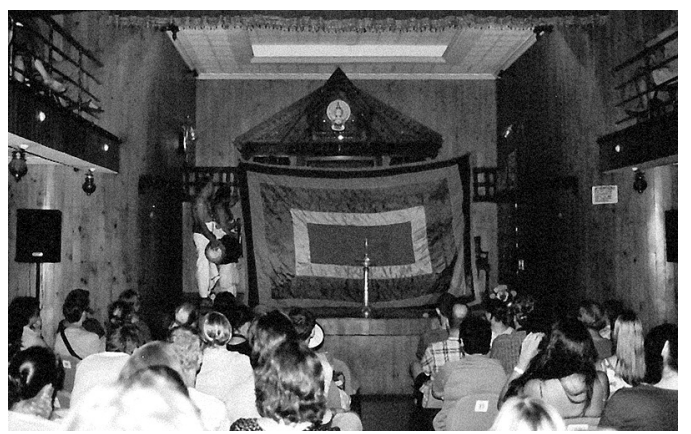

terminologia científica que caracteriza a produção diarística e as cartas de Humboldt, até se alcançar a expressividade e infinita graça do português utilizado por Orta nos seus Colóquios dos simples.

Entre cada recorte ou cena foi tocada ao vivo música original de inspiração goesa, criada ou recriada pelo compositor e maestro Padre Bernardo Cota e executada pelos seus instrumentistas (Gorrete Pinheiro, 1. ${ }^{\circ}$ violino; Anita D'Soouza, $2{ }^{\circ}$ violino; Celine Andrews, viola; Teresa Figueiredo, violoncelo; Susan Badyari, flauta; Rui Lobo, guitarra clássica, a solo). Quase todos vieram de Cunchelim, uma localidade a cerca de $14 \mathrm{~km}$ a norte de Goa.

A representação da peça em português (Alexandre Calado e Sandra Hung) com distribuição de versão em inglês (tradução de Sara de Mello) aos espectadores, teve ainda a particularidade de integrar no espectáculo de Goa dois actores amadores locais (Anju e Prajal Sakhardande, mulher e marido), ensaiados por Isabel Santa Rita Vaz, a quem foi pedido que abrissem a peça, explicando ao público em concanim, qual o assunto da obra. Neste diálogo de línguas e discursos tornou-se mais explícito o nosso propósito de criar uma relação de confiança sem que todos tivéssemos de ser postos à prova por aquilo que a cada um escapava.

A surpresa do espectáculo era ele estar à vista, sob jacarandás e muitas outras espécies vegetais, escutandose todos os pássaros que também nos quiseram visitar e que aos músicos juntavam a sua voz espontânea. As possiveis ambiências naturais que circundaram Humboldt e Orta no seu viajar, renasciam naquela noite de Novembro nos jardins da Fundação Oriente. De dentro para fora do belo edifício seiscentista, em particular, de uma das fachadas, os actores transformavam-se para cada nova personagem e logo para a seguinte, atravessavam arcadas de século para século, contando-se em episódios da vida de Humboldt e de Orta, também com a nossa respiração.

Para lá dos muros de um espaço iluminado a propósito
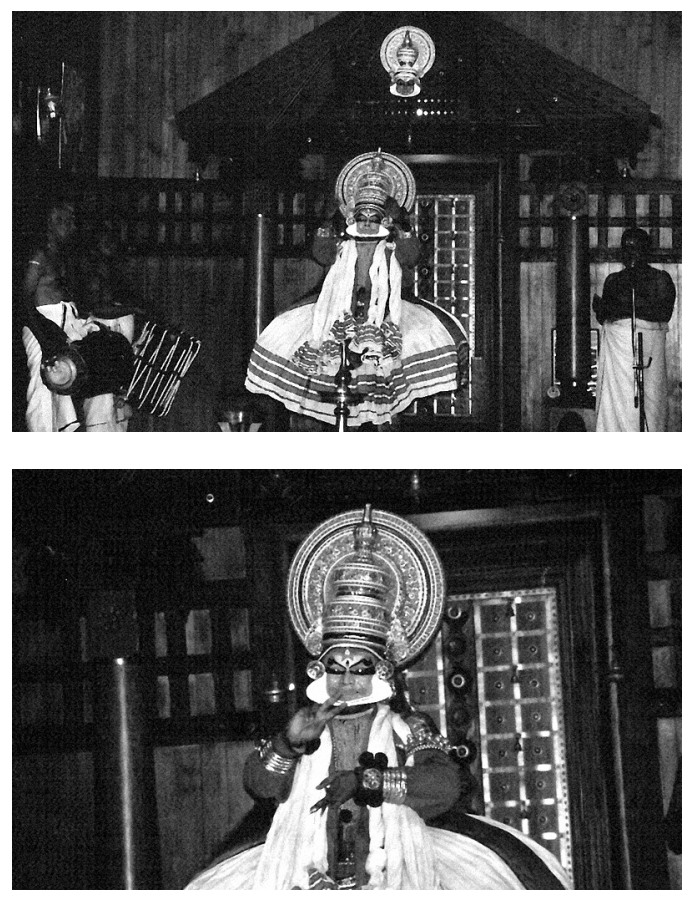

espreitavam homens, mulheres e crianças sem acesso físico ao local onde decorria a representação, mas não menos curiosos perante o que ali se passava. Que terão sentido perante tanta estranheza? Por certo que da experiência coincidente nasceram duas experiências que poderiam não coincidir e, sobretudo, deveriam ser sentidas como separadas. Inseparada adivinhava-se uma coincidência de duas coincidências.

Por mares já há muito navegados ganhara finalmente aquele sentido próprio do lugar, e que só por impedimento incontornável não acontecera também na América do Sul. E foi esse sentido que marcou como um selo vivo uma travessia que talvez não venha a conhecer um fim, porque embora todos saibamos do peso da distância física entre Goa e Lisboa, entre um e outro longe, a verdade é que a bondade de uma suspensão ou de um intervalo não reduz o mundo a um reflexo.

Aqui recordo todos aqueles que de um longe ao outro longe, sem excepção e sem nomeação, acreditaram neste projecto e se sentiram desencaminhados por esta causa nobre e venturosa. De todos sou devedora, pois comigo desempeçaram fio a fio tantas meadas e não deixaram que um só nó ficasse por desatar. 